\title{
Acute Limb Ischemia and Pseudoaneurysm of Femoralis Artery Post Cardiac Catheterization in Pediatric
}

\author{
Hidayanto Perdana $a^{1,{ }^{\star}}$, N. Kurnianingsih ${ }^{2}$ \\ ${ }^{1}$ Resident of Cardiology and Cardiovascular Medicine Departement, ${ }^{2}$ Supervisor of Cardiology and Cardiovascular \\ Medicine Departement, Universitas Brawijaya Malang \\ *correspondence: haperdana@gmail.com
}

\begin{abstract}
Background: Cardiac catheterization is main intervention technique of cardiology and cardiovascular medicine in diagnostic and therapy. It can cause a variety of adverse events, ranging from minor problems without long-term sequelae to major complications requiring immediate corrective action.
\end{abstract}

Case Illustration: A two years old little girl with BMI $18 \mathrm{Kg} / \mathrm{m}^{2}$ underwent diagnostic cardiac catheterization for tetralogy of fallot. She has central cyanosis and secondary policytemia. Catheterization was in general anesthesia, there was difficulities to get arterial access and puncture was done several times. The day after, left lower extrimity found to be ischemic, concomintantly hematome extent to a half area of upper left femoral region and pulsating mass with bruit was in left inguinal. Dupplex ultrasonography diagnosed acute limb ischemia (ALI) with thrombus at artery femoralis communis sinistra and also pseudoaneurysm 1,65 $\mathrm{x}$ $1,67 \mathrm{~cm}$. Intravenous thrombolysis therapy was done with drip steptokinase $2000 \mathrm{IU} / \mathrm{Kg} / \mathrm{hours}$ for 18 hours, stopped after revascularisation has been achieved. Heparin infussion was given $25 \mathrm{IU} / \mathrm{Kg} /$ hours along with streptokinase, then switched to warfarine $0,2 \mathrm{mg} / \mathrm{Kg} / \mathrm{day}$. During thrombolysis, tight observation for bleeding complication, diuresis, and vital sign was done in intermediate intensive care unit. Patient was sent home after eight day with persisting lump and hematome, but hematome and pseudoaneurysm healed 60 daysafterward.

Discussion: Limb threatening ischemia was prioritized in management of ALI with concomitant pseudoaneurysm. For diameter less than $2 \mathrm{~cm}$, pseudoaneurysm which was left untreated may spontaneously resolved. Adult guideline could not be used in pediatric patient. In spite of catheteter directed thrombolysis (CDT), intravenous thrombolysis has satisfying efficacy and safe in pediatric patient. It is strongly recommended to be carefull in dosing, since paucity data of intravenous streptokinase use in pediatric.

Keywords: acute limb ischemia, pseudoaneurysm, cardiac catheterization, intravenous thrombolisis
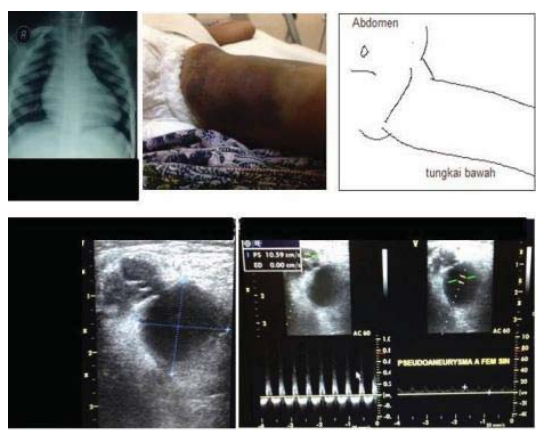

a. Left lower limb

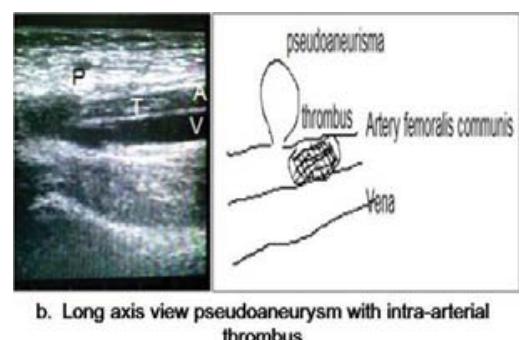

thrombus

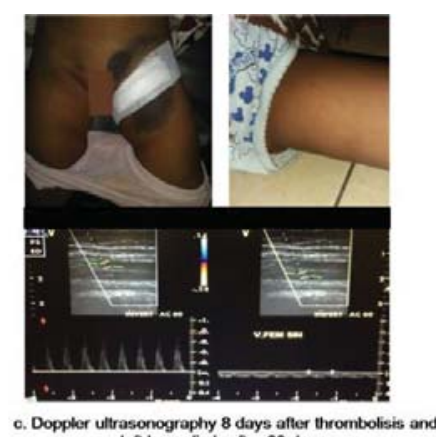

c. Doppter ultrasonography 8 days after throm
lof lower limb afler 60 days. 